\title{
Oral language and story retelling during preschool and primary school years:
}

\section{Developmental patterns and interrelationships}

\begin{abstract}
Oral language and narrative skills constitute very critical factors for children's academic performance and social competence. The aim of the present study was to investigate the developmental patterns of story retelling as well as the relationship between oral language and story retelling in preschool and primary school children. 237 Greekspeaking children (4-5, 5-6 and 6-7 years old) participated in the study. Vocabulary knowledge, phonological awareness, morphological awareness skills and pragmatics were examined through a standardized psychometric test. Story retelling was measured by inviting the children to listen to a story and then retell it. Children's narratives were evaluated according to microstructure (use of conjunctions and lexical cohesion) and macrostructure (story grammar and temporal sequencing) criteria. The results showed that older children performed better than the younger ones across all the oral language and story retelling tasks. Structural Equation Modeling (SEM) revealed that vocabulary skills stand out as a stable predictor across all the three age groups. A new finding was also demonstrated, highlighting that morphological awareness, phonological awareness skills and pragmatics work together with vocabulary skills in diverse patterns at different points of a child's development, in order to support his/her ability to retell a story.
\end{abstract}

Keywords: narrative, story retelling, vocabulary knowledge, phonological awareness skills, morphological awareness skills, pragmatics, preschool children, primary school children 


\section{Retelling}

Retelling has been defined as orally presented causally related events (Peterson, 1990). Efficient early retelling skills are very important both academically and socially (Petersen, Gillam \& Gillam, 2008) In the early years narrative skills facilitate the transition to literacy (Stadler \& Ward, 2005) and predict later academic performance not only in typically developing children but also in children with special educational needs (Spencer \& Slocum, 2010; Diehl, Bennetto \& Young, 2006; Stadler \& Ward, 2005). Additionally, narrative skills are essential for effective communication and social interaction since for example in the event of a social situation, good storytellers are more efficient in using appropriate language than those who face difficulties with narrative production (McCabe and Marshall, 2006).

Narratives have been utilized as ecologically valid assessment tools for unraveling subtle differences in children's language production, when standardized tests fail to be as sensitive assessments (Manolitsis \& Botting, 2011). Advantages of evaluating narratives instead of formal language tests, include the documentation of structural components of child's language such as lexical diversity, syntactic complexity, sentence length along with pragmatic features (the way sentences are linked and referential components) (Kuijper, Hartman, Bogaerds-Hazenberg \& Hendriks, 2017).

Story retelling, which is one type of narratives, is also a measure of listening comprehension since a child must have understood a story in order to be able retell it. (Hagtvet, 2003; Lehto \& Anttila, 2003; Norbury \& Bishop, 2002; Skarakis-Doyle, Dempsey, \& Lee, 2008; Westerveld \& Gillon, 2010).

Narratives are usually evaluated according to microstructure and macrostructure criteria (Westerveld \& Gillon, 2010; Allen, Ukrainetz \& Carswell, 2012), which together determine the quality of a narration (Schneider, Dubé, \& Hayward, 2005). Microstructure 
criteria include cohesion, speech length, grammatical accuracy and linguistic complexity (Halliday \& Hasan, 1976; McCabe \& Rollins, 1994; Curenton, \& Lucas, 2007; Petersen, 2011; Westerveld \& Gillon, 2010). On the other hand, macrostructure can provide information on both (i) the content and structure of the story and (ii) the child's ability to provide a narrative structure and a coherent text (coherence) (Schneider et al., 2005).

\section{Narrative development}

A few studies have investigated developmental differences in children's production of free narratives (mainly) and story retellings (Makinen, Loukusa, Laukkanen, Leinonen, \& Kunnari, 2014; Bohnacker, 2016; Rosch, Florit \& Levorato, 2016). 3-4 years old children's narratives are more of a temporal chain that is not thematically motivated (Muñoz, Gillam, Peña, \& Gulley-Faehnle, 2003). The stories are just a list of events, while they start to understand complex narratives (Kendeou, Bohn-Gettler, White \& Van de Broek, 2008) When a child turns five years old he/she begins to use language to present the plot and can identify the motives of the characters (Munoz et al 2003). According to Stadler and Ward, (2005), children's storytelling skills follow a developmental continuum of five levels (labeling, listing, connecting, sequencing and narrating).

Makinen et. al. (2014) focused on the development of narrative structure and the relationship between narrative productivity (based on picture-elicited narrations). They found significant differences between four- and five-year-olds in productivity and event content and between five- and six-year-olds in referential cohesion. In another study, Bohnacker (2016) reported age effects (5-year-olds vs. 6- to 7-year-olds) for macrostructure production and narrative comprehension in bilingual Swedish- and English-speaking children. Roch, Florit \& Levoraton, (2016) explored narrative production and comprehension in 5-6 and 6-7 years old typically developing Italian-English sequential bilinguals. The results indicated that older 
children outperformed younger ones on all macrostructure measures. Similar developmental findings were reported by Kanellou, Korvesi, Ralli and Mouzaki (2016) in their study with 47 years old Greek children. Last, according to Wehmeier (2021), the narrative comprehension results pointed to significant age effect among three age groups $(4 ; 6-4 ; 11,5 ; 0-5 ; 5,5 ; 6-5 ; 11)$ in children's retellings of stories. Last, in a very recent longitudinal study it was found that the lower the level of picture book comprehension at age 5, the steeper the improvement of it from age 5 to age 9 (Lepolam Kajames, Laakkonen \& Niemi, 2020).

Nevertheless, to date, there is limited information documenting growth patterns in narrative development of typically developing children, since. most of the studies have studied narrative development mainly using free narratives and not story retellings as well as including in their samples bilingual children or children with developmental difficulties. Previous studies also, mainly focused on developmental differences on macrostructure and not microstructure criteria.

\section{The relationship between oral language skills and story retelling}

Story retelling is a complicated process which involves a range of abilities, such as receptive and expressive language skills as well as memory and attention. More specifically, language skills involve phonology, vocabulary, syntax, semantics and speech structure. Nonlinguistic knowledge of the subject, content and overall knowledge of how the world works are also required (Allen, et al., 2012; Buck, 2001; Vandergrift, 2004). According to Diehl, Bennetto \& Young (2006): «The process of retelling a story involves understanding the story, holding the story in memory, and constructing the retelling in a manner that is understandable by the listener [...] In general, people use the largest, most general frame to organize their narrative, and put stories into schemas with settings, plots, and episodes». 
Vocabulary constitutes the basis for language learning. It has been demonstrated that receptive vocabulary is a significant predictor of narrative listening comprehension at the ages of 4 and 6 years Kendeou et. al. (2008; Roch \& Hrzika, 2021). It has also been found that both receptive and expressive vocabulary are correlated with story retelling in preschool children (Lepola, Lynch, Silvén, \& Niemi,2012; Jalongo \& Sobolak, 2011). However, most of the previous studies have used mainly a single measure for assessing vocabulary e.g. multiple-choice task, or word definition and word naming tasks. The concurrent assessment of vocabulary knowledge with a variant of measures (listening comprehension, receptive vocabulary, naming and word definition tasks), as such that will be employed in the present study could provide the researchers, with a stronger latent variable of vocabulary skill, in order to better understand the impact of different vocabulary skills on retelling.

Phonological skills refer to the awareness of the sound structure of spoken words, which must be mapped onto letters to read (Saygin, Norton, Osher, Beach, Cyr, OzernovPalchik et al., 2013). From a theoretical point of view, Bialystok $(1986,1993,1999)$ provides a framework to support an association between phonological awareness skills and narrative story structure. Her framework is premised on two hypotheses: (a) that metalinguistic awareness is continuous with children's developing language proficiency (Farrar, Ashwell, \& Maag, 2005); and (b) that all language use is being supported by common underlying cognitive processes -representational analysis and cognitive control- (Bialystok, 1993). Representational analysis refers to the ability to represent the structure of language; cognitive control refers to the ability to attend to relevant aspects of a representation in problem solving (Bialystok, 1999). Phonological awareness tasks, which require children to selectively attend to the sound structure of language while disregarding meaning, place particularly high demands on both representational analysis and cognitive control. Story retelling, like phonological awareness, requires selective attention to structure, since successful storytelling 
is dependent on the narrator's attention to story structure (McKeough, Tourigny, Bird, \& Romaine, 2008).

Although, the widely held position that emergent literacy, oral language and coderelated skills, are interrelated in the preschool years, only very few studies have identified relationships between phonological awareness skills and narrative structure in preschool children (Hipfner-Boucher, Milburn,. Weitzman, Greenberg, Pelletier,Girolametto, 2014). The present study aims to add evidence to the previous under researched area.

Morphological skills refer to the appreciation of the morphemic structure of words and the ability to recognize and manipulate that structure (bases/stems, suffixes, prefixes) (Kuo \& Anderson, 2006). Morphological skills, another language aspect has been already identified to be related to reading and spelling skills both in English, as well as in other languages such as Greek (Diamanti, Benaki, Mouzaki, Ralli, Antoniou, Papaioannou \& Protopapas, 2018).

As retelling revolves around causes and consequences of different actions within a broader framework that needs to be understood by the listener, linguistic structures like grammatical units and lexical diversity are very important features. In order to establish temporal and causal relations in the retelling, a child needs to utilize complex syntax and morphology as well as explicit vocabulary, effective use of pronouns and efficient employment of temporal connectives (Capps, Losh \& Thurber, 2000; Losh \& Capps, 2003). A small group of studies have supported that there is a relationship between morphological skills and vocabulary knowledge in school age children (Wagner, Muse, \& Tannenbaum, 2007). Nevertheless, due to the lack of research, the role of morphological skills in retelling is not very well established. Therefore, there is a need to investigate the role of morphological skills in children's ability to retell a story.

Story retelling also require pragmatic skills. Pragmatics refers to the communicative intentions of speakers and depends on the linguistic context (Martin \& McDonald, 2003; 
Yule, 2006). When a child retells a story needs to apply several pragmatics aspects, such as put the events in logical sequence, use appropriate language in order to produce a cohesive discourse, with a good narrative structure, taking account the listener, etc. As such, it is hypothesized that pragmatics should be related to a child's ability to retell a story. However, there is no evidence to support such a hypothesis. Although it is known that the evaluation of a narrative is also a way of measuring pragmatic knowledge (Botting, 2002; Fernández, 2013) to our knowledge, the role of children's pragmatics' in story retelling has not been explored.

Additionally, there are no studies investigating how the above possible relationships between oral language skills and story- retelling may change over time, except for a very recent longitudinal study exploring only the role of vocabulary in narrative picture-book comprehension through a retelling task and prompted comprehension questions in 5 to 9 years old children. The results of the above study revealed that vocabulary uniquely contributed to the concurrent level of picture book comprehension for preschoolers but not for the older children. (Lepolam, Kajames, Laakkonen \& Niemi, 2020)

\section{The present study}

Previous studies have explored narrative development mainly using free narratives and not story retellings as well as including in their samples bilingual children or children with developmental difficulties. They have also mainly focused on developmental differences on macrostructure and not microstructure criteria. Therefore to date, there is limited information documenting growth patterns in narrative development of typically developing children both in microstructure and macrostructure criteria.

Also, it has become evident that story retelling presupposes the interplay of the different language subsystems, however most of the studies have investigated only one aspect 
of vocabulary knowledge or phonological skills, without having explored the contribution of morphological skills or pragmatics in children's ability to retell a story. Thus, there is a lack of studies focusing on the contribution of many aspects of oral language to story retelling, as well as whether this relationship may change over time. Additionally, most of the studies have either included in their sample bilingual children (Bedore, Pena, Gillam, \& Ho, 2010; Fiestas, \& Peña, 2004) or children with Developmental Language Disorder mainly focusing on describing their oral language and narrative skills and not a possible relationship between them (Vandewalle, Boets, Boons, Ghesquière and Zink' (2012). There is a lack of studies examining the role of oral language skills in monolingual typically developing children.

Therefore, the aim of the present study was to investigate the relationship between a set of oral language components (vocabulary knowledge, phonological and morphological skills and pragmatics) with story retelling in typically developing preschool and primary school children. The research questions of the present study were the following: (1). Are there developmental differences in children's oral language and narrative skills? (2) Is there a relationship between oral language and story retelling? For the first research question developmental differences were expected, while for the second research question it was expected that different oral language skills would support story retelling.

\section{Methods}

\section{Participants}

Two hundred and thirty-seven Greek-speaking children mostly from middle class socioeconomic backgrounds coming from various regions of Greece participated in the study. The data of the present study have been drawn from the research project "The Foundation of Reading and Writing in a Transparent Orthography: Oral language development and early literacy skills" that had been partially funded by a University in Greece. 
Specifically, the sample included 237 children separated into three age groups, according to their grade of schooling. The first age group consisted of 79 children $(33.3 \%)$ between 4 to 5 years old (mean age: 4,5), who attended pre-Kindergarten, the second one included 58 children (24.5\%) from 5 to 6 years old (mean age: 5,5), who attended Kindergarten, and the third group included 100 children (42\%) between 6 to 7 years old (mean age: 6,5) who attended year one of primary school. 98 children of the sample were boys (41\%) and 139 were girls (59\%). The children had to have Greek as their mother tongue, while children with special educational needs did not take part in the study.

\section{Measures}

Oral language and story retelling were assessed with the standardized digital psychometric tool "Logometro" was administered (Mouzaki, Ralli, Antoniou, Diamanti, Papaioannou, 2016). "Logometro" includes a set of tasks assessing the different language subsystems (phonology, morphology, semantics, pragmatics, narrative skills). The specific tasks which are included in each of the subsystems are described into detail below:

\section{Oral language measures}

\section{Vocabulary knowledge tasks}

Vocabulary knowledge was assessed with four different tasks from Logometro test (listening comprehension task, receptive vocabulary task, naming task, word definition task). In the Listening comprehension task (Cronbach's $\alpha=0.78$ ) each child was invited to look carefully at four different images and then to choose the appropriate image. For example, each child was asked to «point to the boy with short hair» with distractors a boy with long hair, a girl with short hair and a girl with long hair. In the receptive vocabulary task (Cronbach's $\alpha=0.88$ ), each child was presented with four different images and was asked to 
choose the image that best represented the word that was heard. In the naming task (Cronbach's $\alpha=0.72$ ), each child was asked to look at a picture and then to name it. Last, in the word definition task (Cronbach's $\alpha=0.93$ ) each child was asked to give a brief definition of a series of words.

\section{Phonological awareness and processing tasks}

In order to assess children's phonological awareness skills in a comprehensive manner 8 different tasks from the same psychometric battery were administered: (a) identification of similarities task (syllable level), b) identification of similarities task (phoneme level), c) synthesis task (syllable level), d) synthesis task (phoneme level), e) syllabic segmentation task, f) phonemic segmentation task, g) syllabic elimination task, and h) phonemic elimination task. In the identification of similarities task (syllable level) (Cronbach's $\alpha=0.84$ ) each child was listening to the label of a target image as well as to the labels of three other images and then he/she had to choose which of the three images begun with the same syllable as the target image. In the identification of similarities task (phoneme level) (Cronbach's $\alpha=0.84$ ) each child was listening to the label of a target image as well as to the labels of three other images and then had to choose which of the three images begun with the same phoneme as the target. In the syllabic synthesis task (Cronbach's $\alpha=0.89$ ) each child was asked to compose words from a series of syllables that were pronounced separately, while in the phonemic synthesis task (Cronbach's $\alpha=0.93$ ) each child had to compose words from a series of phonemes that were pronounced separately. Last, in the syllabic segmentation task, (Cronbach's $\alpha=0.95$ ), and phonemic segmentation task (Cronbach's $\alpha=0.95$ ) each child had to listen to a word and then was asked to analyze it in syllables as well as in phonemes correspondingly, while in the syllabic deletion task, (Cronbach's $\alpha=0.94$ ) and phonemic deletion taska (Cronbach's $\alpha=0.92$ ) each child was asked to listen carefully to a word and 
then to repeat it by deleting a portion of it which was an entire syllable in the case of syllabic deletion task and a phoneme in the case of phonemic deletion task.

\section{Morphological awareness tasks}

Morphological awareness skills were assessed through 4 different tasks, as described in Diamanti, Benaki, Mouzaki, Ralli, Antoniou \& Papaioannou (2018). The first and the second task evaluated the implicit knowledge of morphology, while the latter two evaluated the explicit knowledge of the morphology. Specifically, children were presented with a series of pictures. At the same time two sentences were heard for each picture. Each child had to choose the sentence that contained the derived adjective or noun (with a different derivational suffix and thereby matched or mismatched the sentence context) (Cronbach's $\alpha=0.61$ ). The second task tested children's ability to identify and select inflectional morphemes at verb suffixes (in present tense, third person, singular and plural) and at noun suffixes (neutral gender, singular and plural) by using non-words (Cronbach's $\alpha=0.80$ ). The third task was used in order to assess the ability to form and produce productive morphemes in nouns and adjectives (e.g., "The sea deepens. The sea is... requiring “deep”) (Cronbach's $\alpha=0.84)$. The fourth task evaluated the ability to form and produce inflectional morphemes in verbs (applying present tense, third person, singular and plural morphemes) and in nouns (applying neutral gender, singular and plural) by using non- words, (Cronbach's $\alpha=0.95$ ). For these tasks, children were provided with pictures that introduced heroes-animals along with a verbal description including the pseudo words. The heroes-animals used their own "strange language" in order to account for the non- word language. Children were also provided with the beginning of a second sentence, matching the second picture, up to the subject of the verb, and were asked to change the non-word number (from singular to plural or from plural 
to singular) accordingly (e.g., "Boy plays with tuppy (pseudo word for puppy). Boy plays with.... requiring "tuppys”).

\section{Pragmatics task}

Pragmatic skills were assessed through a series of tasks assessing children's ability to produce speech acts (Cronbach's $\alpha=0.81$ ). Each child was asked to respond in the most appropriate way to the examiner's questions, regarding (a) the interpretation of the communicative situation presented in the picture (Cronbach's $\alpha=0.81$ ), (b) the intention/ability to communicate (Cronbach's $\alpha=0.81$ ), (c) the response to communication (Cronbach's $\alpha=0.81)$ and $(\mathrm{d})$ the interactional skills that are related to the contextual variation (Cronbach's $\alpha=0.81$ ). Twenty-one questions corresponded to 11 illustrated scenarios. Specifically, each scenario included 1 to 3 questions that required a verbal response. Each response could be scored with 1 to 7 points, depending on the quality of the provided answer. For example, in one scenario a happy boy is sitting on a swing and two sad children are looking at him. The corresponding question to the child-participant was: "What should the children say to the boy in order to swing too?" The child had to provide an answer that corresponded to a number of criteria and is rich enough to: show kindness (e.g. please); request a specific reaction (e.g. get down from the swing); show emotional expression (e.g. we are sad that we cannot play too); gain and hold the attention (e.g. Use the word you); show un derstanding of the speakers intention (the examinee should understand that the children are requesting something); use verbal communication and show communicative skills in order to earn the highest score in this scenario.

\section{Story retelling task}


Story retelling skills were assessed with the use of six simple pictures which accompanied a story (one short story for all age groups). Each child was invited to listen carefully to a story presented orally by the researcher and then was asked to retell it. The story had a simple story structure: three leading roles, an introduction, an event, a problem and a solution. The theme was interesting and compatible with the existing knowledge of most children (Buck, 2001) referring to a simple incident of two children playing in a park.

\section{Coding of children's story retellings}

Children's story retellings were analyzed according both to microstructure and macrostructure criteria. The specific criteria which were evaluated for microstructure were: (a) use of conjunctions (Halliday \& Hasan, 1976; McCabe \& Rollins, 1994; Peterson \& McCabe, 1991) and (b) use of lexical cohesion (relevance and quality of words) (Halliday \& Hasan, 1976). Story retellings with no use of conjunctions (i.e. labelling) were scored with 0. Retellings using only few coordinating conjunctions (i.e. "and") received 1 point while retellings using coordinating, subordinating and/or correlative conjunctions (and contained more grammatically complex sentences) were scored with 2 points. Macrostructure was evaluated with the Story Grammar framework (Stein \& Glenn, 1979) and temporal sequencing of actions (Mandler \& Johnson, 1977; Stein \& Albro, 1997, as referred to Hipfner-Boucher, Milburn, Weitzman, Greenberg, Pelletier \& Girolametto, 2014). The Story Grammar included (a) an introduction (convention and/ or place/ time/ heroes), (b) development of characters (state of mind and feelings of heroes), (c) report of the problem (how and/ or why and solution), and (d) result/conclusion. Temporal sequencing refers to the episodic structure and succession of story elements. No score was assigned to retellings with errors in the order of the episodes, while simple repetitions of events or minor gaps received 1 point. Retellings containing accurate story-episodes succession were scored with 2 points. 
Retelling accuracy as well as vocabulary was assessed. For all the criteria used, score «0» corresponded to "minimum/immature" performance, score "1" corresponded to "developing" performance, while score "2" referred to "sufficient / mature" performance.

In order to have a holistic assessment score of children's narratives, individual total scores were composed (range 0-12) by summing the scores for all six microstructure and macrostructure criteria (conjunctions/cohesion, temporal sequencing, introduction, character development, problem reporting, result/cohesion). Coding and scoring of the retellings according to the above-mentioned criteria was held by four raters in a randomly selected sample of retellings $(\mathrm{N}=30)$ randomly selected. Agreement percentage was calculated for each one of the retelling criteria. Interrater agreement was on average higher than $90 \%$.

\section{Results}

Two types of analyses were applied. Firstly, a One-Way ANOVA was applied in order to investigate developmental differences as a function of age. Second, we used SEM to identify the onset, offset and rate of change for developmental phases among vocabulary knowledge, phonological skills, morphological skills, pragmatics and story retelling.

\section{Children's oral language and story-retelling skills across age groups}

One-way ANOVA was conducted to check developmental differences in the language measures (Table 1). Children performed better as they got older across all the oral language skills (listening comprehension: $F(2,236)=49,89, p<0.01$, receptive vocabulary: $F(2,236)=$ $66,35, p<0.01$, word definition: $F(2,236)=37,08, p<0.01$, naming: $F(2,236)=23,86$, p $<0.01$, phonological skills: $F(2,236)=139,72, p<0.01$, morphological skills: $F(2,236)=57,53$, $p<0.01)$, pragmatics: $F(2,236)=20,81, p<0.01)$. Additionally, one-way ANOVA was also carried out in order to investigate developmental differences in children's retellings. It was 
also found that children's retellings improved with age as a whole $(F(2,236)=11,29$, $p<0.01$ ) as well as according to the specific criteria. (conjunction: $F(2,236)=49,89, p<0.01$, lexical cohesion: $F(2,236)=4,59, p<0.01$, story grammar elements: $F(2,236)=9,18$, $p<0.01$, temporal sequencing of actions \& events: $F(2,236)=2,96, p<0.01)$.

\section{[Insert Table 1]}

The relationship between oral language skills and story retelling across age groups

In order to better explore, in more depth the relationship between oral language skills (vocabulary knowledge, phonological skills, morphological skills, pragmatics) and story retelling across age groups, SEM analysis was applied to the data. To capture the development of retelling skills, 3 different age groups were examined and confirmatory factor analysis was used to test the latent constructs.

Firstly, several models for group equivalence were tested but as indicated by the fit indices, these models did not yield a good fit to the data. Next, separate models were fitted for each age cohort (4-5, 5-6 \& 6-7). In order to evaluate the goodness of fit of each model to the data, we report the model chi-square statistic associated with the $p$ value, the Goodnessof-fit statistic (GFI), the Normed-fit index (NFI), the Comparative fit index (CFI), the Root mean square residual (RMR) and standardized root mean square residual (SRMR) (Hooper, Coughlan, \& Mullen, 2008). A non-significant value of the chi-square statistic indicates a good fit. In addition, the test is sensitive to sample size and should be considered in relation to its degrees of freedom (i.e., dividing chi-square value by its degrees of freedom should result in a value below 2, indicating a good model fit; Maruyama, 1998). GFI, AGFI range between 0 and 1 and it is generally accepted that values of 0.90 or greater indicate well-fitting 
models. As with GFI, AGFI, the NFI and CFI values greater than 0.90 indicating a good fit. Finally, an RMSEA of between 0.08 to 0.10 provides a mediocre fit and below 0.08 shows a good fit (MacCallum, Browne, \& Sugawara, 1996).

Several types of models were pitted against each other. In the most refined version of these models, the following latent variables were built. Indicators for the vocabulary skills latent variable were listening comprehension, receptive vocabulary, naming and word definition. Indicators for the retelling skills latent variable were use of conjunctions, lexical cohesion, story grammar and temporal sequencing.

Fitting the Model for the First Cohort (Ages 4-5)

Figure 1 depicts the fitted model for the first cohort of children with standardized parameter estimates. The assumption that prevails is that during the first preschool years vocabulary skills predict morphological skills since the development of vocabulary skills precedes morphological skills. Morphological skills are assumed to predict retelling skills (composite score and its components). As indicated by the fit indices, $\chi^{2}(25, N=79)=35.95$, $p=.72\left(\chi^{2} / d f=1.44\right) ; \mathrm{CFI}=.92 ; \mathrm{NFI}=.89 ; \mathrm{GFI}=.96 ; \mathrm{RMSEA}=.08$ and the $\mathrm{RMR}=.08$, the model yielded a good fit to the data. The relative magnitude and significance of the standardized coefficients show that the relationship between vocabulary and morphological skills is strong (with vocabulary skills predicting $84 \%$ of the variance in morphological skills) but the relationship between morphological and retelling skills was not so strong. Therefore, according to the model, for the 4-5 years old children, vocabulary skills indirectly predict retelling skills through morphological skills.

[Insert Figure 1] 
Fitting the Model for the Second Cohort (Ages 5-6)

The second cohort indicators for the vocabulary skills latent variable were again the same as above as well as for the retelling skill latent variable. Figure 2 depicts the fitted model for the second cohort of children with standardized parameter estimates. Consistent with the model fitted for the first cohort, vocabulary skills predict the morphological and phonological skills. It is again assumed that morphological skills play a vital role in preceding and, therefore, predicting retelling skill in this age group. As indicated by the fit indices, $\chi^{2}(32, N=58)=31.17, p=.51\left(\chi^{2} / d f=.97\right) ; \mathrm{CFI}=1.0 ; \mathrm{NFI}=.90 ; \mathrm{GFI}=.91$; RMSEA=.00 and the RMR=. 07, the model yielded a good fit to the data.

[Insert Figure 2]

The relative magnitude and significance of the standardized coefficients show that the relationship between vocabulary skills and morphological skill was very strong as well as the relationship between vocabulary skills and phonological skill. Furthermore, the standardized coefficients show that the relationship between morphological skills and retelling skills was strong while the relationship between phonological skills and retelling skills was very weak and not statistically significant. To sum up, according to the model, vocabulary skills indirectly predict story retelling through morphological and phonological skills for the 5-6 years old children,

Fitting the Model for the Third Cohort (Ages 6-7)

For the third age cohort (6-7 years old), indicators for the latent variables were the same as for the above two cohorts. Figure 3 depicts the fitted model for the third cohort of children with standardized parameter estimates. Consistent with the models fitted for the first and 
second cohort, vocabulary skills are supposed to predict morphological skills and that vocabulary skills predict pragmatics skills. In addition, both pragmatic skills and morphological skills seem to independently predict retelling skills. As indicated by the fit indices, $\chi^{2}(33, \mathrm{~N}=100)=29.29, \mathrm{p}=.65\left(\chi^{2} / \mathrm{df}=.89\right) ; \mathrm{CFI}=1.0 ; \mathrm{NFI}=.90 ; \mathrm{GFI}=.94$; RMSEA $=.00$ and the $\mathrm{RMR}=.05$, the model yielded a good fit to the data. According to this model, vocabulary skills predict story retelling through pragmatics and phonological skills. for the 6-7 years old children.

[Figure 3]

\section{Testing Alternative Models}

The assumed models fit the data very well as we can see by the goodness-of-fit. However, it is possible that our data support other models that are also theoretically meaningful. For example, one might object that a model for the first cohort placing also phonological skills in the hierarchy might fit equally well. To test this hypothesis as well as others for the two more cohorts, a series of alternative models for each cohort was tested and compared with models in Figures 1, 2 and 3.

The alternative model that we tested for the first cohort differed from the prototype model since two more variables were added; the phonological and the pragmatic skills. Thus, this model assumes that all the variables were predictors for the retelling skills. The overall fit of this model was not good, $\chi^{2}(41, N=79)=87.45, p=.00\left(\chi^{2} / d f=2.13\right)$; CFI= .86; NFI=.78; $\mathrm{GFI}=.83$; $\mathrm{RMSEA}=.12$ and the $\mathrm{RMR}=$. 09. In addition, the prototype model had smaller RMSEA and AIC.

Following the same rationale, one alternative model was tested for the second cohort. This model differed from the prototype model in that we change the phonological parameter 
with the pragmatics. Thus, this model assumes that the morphological and pragmatic skills were predictors for the retelling skills. The overall fit of this model was not good, $\chi^{2}(33, \mathrm{~N}=$ $58)=51.96, \mathrm{p}=.00\left(\chi^{2} / \mathrm{df}=1.57\right) ; \mathrm{CFI}=.93 ; \mathrm{NFI}=.83 ; \mathrm{GFI}=.85 ; \mathrm{RMSEA}=.10$ and the $\mathrm{RMR}=$. 09. In addition, the prototype model had smaller RMSEA and AIC.

Following the exact same rationale, the third one alternative model was tested. This model differed from the prototype model in that the morphological skills parameter was changed with the phonological skills. Thus, this model assumes that all the variables, the morphological skill and pragmatics were predictors for the retelling skill. The overall fit of this model was good, $\chi^{2}(33, \mathrm{~N}=100)=35.76, \mathrm{p}=.34\left(\chi^{2} / \mathrm{df}=1.08\right) ; \mathrm{CFI}=.99 ; \mathrm{NFI}=.90$; GFI=.94; RMSEA=.03 and the RMR=. 06. However, the prototype model had smaller RMSEA and AIC.

There are many more similarities than differences between the three age groups. Specifically, morphological skills are generally similarly related to retelling in the first two age groups as they have a predictive role in retelling from 4 to 6 years old. In the second age group however, phonological skills play a predictive role in retelling together with morphological skills. Differently, in the third age group pragmatic and phonological skills seem to mediate the relationship between vocabulary and retelling.

\section{Discussion}

The aim of the present study was to investigate the developmental patterns of story retellings as well as the relationship between oral language skills and story retelling during preschool and primary school years.

According to the results, statistically significant developmental differences were found in children's performance across all oral language tasks, with the older children performing better in comparison to the younger age groups (Hipfner- Boucher et al., 2014; Lepola et al., 
2012; Westerveld \& Gillon, 2010). Older children also tended to have higher performance across all the story retelling microstructure and macrostructure criteria than the younger ones. The above pattern of narrative development is similar with the results of previous studies, regarding macrostructure criteria (Bohnacker, 2016; Makinen et. al. 2014; Roch, Florit \& Levorato, 2016; Lepolam Kajames, Laakkonen \& Niemi, 2020; Wehmeier, 2021). Nevertheless, the present study, adds new evidence for this developmental growth in in relation to also microstructure criteria.

Regarding the relationship between oral language skills and story retelling, similarities and differences were identified across the different age groups. More specifically, all the vocabulary skills (listening comprehension, receptive vocabulary, naming, word definition) predicted story retelling through morphological skills for the 4-5 years old children. The findings about the predictive role of vocabulary skills are consistent with previous studies, However, they also extend them by demonstrating the crucial role of different levels of vocabulary knowledge in story retelling, such as listening comprehension, receptive vocabulary, naming and word definition. Additionally, our data further suggest the indirect role of morphological awareness skills in the above relationship. It seems vocabulary that knowledge works together with morphological awareness skills (e.g. grammatical units, pronouns, temporal connectives, lexical diversity) in order for a child to be able to establish temporal and causal relations to retell efficiently a story (Capps, Losh \& Thurber, 2000; Losh \& Capps, 2003).

For the 5-6 years old, vocabulary skills had also contributed story retelling through not only morphological but also phonological awareness skills. A possible explanation could be that at this age group, children improve their phonological awareness skills by participating in phonological awareness activities in their classrooms according to the curriculum. Thus, their 
vocabulary skills through the improved phonological awareness skills support story retelling performance.

For the $1^{\text {st }}$ grade primary school children (6-7 years old) vocabulary skills still also contributed to story retelling through phonological skills and pragmatics. The complementary role of pragmatics could be possibly explained by the fact that when a child retells a story needs to apply several pragmatics aspects, such as put the events in logical sequence, use appropriate language in order to produce a cohesive discourse, with a good narrative structure, taking account the listener, etc. The above skills seem to start make their appearance in this age group making a significant contribution along with vocabulary skills to story retelling.

In sum, the concurrent "reading" of the three models, demonstrates that the role of vocabulary skills for story retelling is critical and very stable across all the three age groups (Lepola et al., 2012). Additionally, a closer look at the three models together highlights that as the children get older a new language component is being added in the model as another contributor to their ability to retell a story, probably showing a developmental trend. Thus, for the 4-5 years old, except from vocabulary skills, morphological skills contribute to story retelling, for the 5-6 years old children apart from vocabulary and morphological awareness skills, phonological awareness skills appear in the model, while for the 6-7 years old, another new language aspect comes forward apart from the previous ones which is pragmatics. It seems that, apart from vocabulary skills which stand out as a stable predictor across all the three age groups, morphological awareness, phonological awareness and pragmatics work together with vocabulary skills in diverse patterns at different points of a child's development, in order to support his/her ability to retell a story.

The present study was an exploratory study, a first attempt to our knowledge to investigate the role of different oral language skills simultaneously in children's ability to 
retell a story, using a cross-sectional design with three age groups during the early school years. Future studies could further study the role of different oral language skills in retelling, trying to unfold the nature of interplay between vocabulary skills and the other language skills, such as morphological, phonological and pragmatics in children's ability to retell a story.

\section{Limitations and Future Directions}

In conclusion, the results of the present study extend the limited number of previous research about the developmental growth of children's narrative ability as this was assessed through story retelling. Also, it further expand our understanding about the link between oral language and story retelling, by adding new evidence about the concurrent contribution of different levels of vocabulary knowledge as this was assessed by a set of different tasks (listening comprehension, receptive vocabulary, naming, word definition). Furthermore, the present study highlighted for the first time to our knowledge the simultaneous contribution apart from vocabulary skills, of other language aspects such as phonological awareness skills, morphological awareness skills and pragmatics to story retelling.

Nevertheless, future studies need to be carried out since narrative development has not received enough attention in language research like other areas of language, as reading and spelling. It is very important future studies to examine the above relationships in other languages as well as with longitudinal design that will follow the same group of children in order to strengthen the above assumptions.

Our findings regarding the crucial role of vocabulary skills in relation to other language domains for story retelling can have significant practical implications as they support the need for fostering an array of oral language skills during preschool and primary school years. Moreover, such findings about the interplay between different oral language skills and story 
retelling need to be replicated, as they may allow early identification of risk factors related to narrative difficulties and enable educators to enhance those skills at a very young age.

\section{References}

Allen, M. M., Ukrainetz, T. A., \& Carswell, A. L. (2012). The Narrative Language Performance of Three Types of At-Risk First-Grade Readers. Language, Speech, and Hearing Services in Schools, 43, 205-221. doi: 10.1044/0161-1461(2011/11-0024)

Banney, R. M., Harper-Hill, K., \& Arnott, W. L. (2015). The Autism Diagnostic Observation Schedule and narrative assessment: Evidence for specific narrative impairments in autism spectrum disorders. International journal of speech-language pathology, 17(2), 159-171.

Barrett, M. (Ed.). (2016). The development of language. Psychology Press.

Bedore, L. M., Pena, E. D., Gillam, R. B., \& Ho, T. H. (2010). Language sample measures and language ability in Spanish-English bilingual kindergarteners. Journal of communication disorders, 43(6), 498-510.

Benjamins, J., \& Gagarina, N. (2021). Developing Narrative Comprehension. Multilingual assessment instrument for narratives. Narrative comprehension by Croatian-Italian bilingual children 5-7 years old. The role of receptive vocabulary and sentence comprehension. (Ed. Ute Bohnacker and Natalia Gagarina). Studies in Bilingualism, 171-196.

Bialystok, E. (1986). Factors in the growth of linguistic awareness. Child development, 498510.

Bialystok, E. (1993). Metalinguistic awareness: The development of children's representations of language. In C. Pratt \& A. F. Garton (Eds.), Systems of representation in children: Development and use (pp. 211-233). London, UK: John

Bialystok, E. (1999). Cognitive complexity and attentional control in the bilingual mind. Child development, 70(3), 636-644. 
Bohnacker, U. T. E. (2016). Tell me a story in English or Swedish: Narrative production and comprehension in bilingual preschoolers and first graders. Applied Psycholinguistics, 37(1), 19.

Botting, N. (2002). Narrative as a tool for the assessment of linguistic and pragmatic impairments. Child Language Teaching and Therapy, 18, 1-21. doi: $10.1191 / 0265659002$ ct224oa

Buck, G. (2001). Assessing listening. Cambridge, UK: Cambridge University Press.

Capps, L., Losh, M. \& Thurber, C. (2000). The Frog Ate the Bug and Made his Mouth Sad": Narrative Competence in Children with Autism. Journal of Abnormal Child Psychology, 28, 193. https://doi.org/10.1023/A:1005126915631

Curenton, M. S., \& Lucas, M. T. (2007). Assessing narrative development. In K. L. Pence (Ed.), Assessment in emergent literacy (pp. 377-432). San Diego, CA: Plural.

Diamanti, V., Benaki, A., Mouzaki, A., Ralli, A., Antoniou, F., Papaioannou, S., \& Protopapas, A. (2018). Development of early morphological awareness in Greek: epilinguistic versus metalinguistic and inflectional versus derivational awareness. Applied Psycholinguistics, 1-23.

Diehl, J. J., Bennetto, L., \& Young, E. C. (2006). Story recall and narrative coherence of high-functioning children with autism spectrum disorders. Journal of abnormal child psychology, 34, 83-98.

Dufva, M., Niemi, P., \& Voeten, M. J. M. (2001). The role of phonological memory, word recognition, and comprehension skills in reading development: From preschool to grade 2. Reading and Writing, 14(1), 91-117. doi: 10.1023/A:1008186801932

Farrar, M. J., Ashwell, S., \& Maag, L. (2005). The emergence of phonological awareness: Connections to language and theory of mind development. First language, 25(2), 157-172. 
Fernández, C. (2013). Mindful storytellers: Emerging pragmatics and theory of mind development. First Language, 33 (1), 20-46. doi: 10.1177/0142723711422633

Fiestas, C. E., \& Peña, E. D. (2004). Narrative discourse in bilingual children. Language, Speech, and Hearing Services in Schools.

Hagtvet, B. E. (2003). Listening comprehension and reading comprehension in poor decoders: Evidence for the importance of syntactic and semantic skills as well as phonological skills. Reading and Writing: An Interdisciplinary Journal, 16 (6), 505-539. doi: 10.1023/A:1025521722900

Halliday, M. A. K., \& Hasan, R. (1976). Cohesion in English. London: Longman.

Hipfner-Boucher, K., Milburn, T., Weitzman, E., Greenberg, J., Pelletier, J., \& Girolametto L. (2014). Relationships between preschoolers' oral language and phonological awareness. First Language, 34 (2), 178-197. doi: 10.1177/0142723714525945

Jalongo, M. R., \& Sobolak, M. J. (2011). Supporting Young Children's Vocabulary Growth: The Challenges, the Benefits, and Evidence-Based Strategies. Early childhood education journal, 38 (6), 421-429. doi: 10.1007/s10643-010-0433-x

Kanellou, M., Korvesi, E., Ralli, A., \& Mouzaki, A. (2016). The narrative skills in preschool and first grade children. Preschool and Primary Education.

Kendeou, P., Bohn-Gettler, C., White, M. J., \& Van de Broek, P. (2008). Children's inference generation across different media. Journal of Research in Reading, 31 (3), 259-272. doi: 10.1111/j.1467-9817.2008.00370.x

Kuo, L. J., \& Anderson, R. C. (2006). Morphological awareness and learning to read: A cross-language perspective. Educational Psychologist, 41(3), 161-180.

Kuijper, S. J., Hartman, C. A., Bogaerds-Hazenberg, S., \& Hendriks, P. (2017). Narrative production in children with autism spectrum disorder (ASD) and children with attention 
deficit/hyperactivity disorder (ADHD): Similarities and differences. Journal of Abnormal Psychology, 126, 63.

Lehto J. E., \& Anttila M. (2003). Listening Comprehension in Primary Level Grades Two, Four and Six. Scandinavian Journal of Educational Research, 4(2), 133-143. doi: $10.1080 / 00313830308615$

Lepola, J., Kajamies, A., Laakkonen, E., \& Niemi, P. (2020). Vocabulary, metacognitive knowledge and task orientation as predictors of narrative picture book comprehension: from preschool to grade 3. Reading and Writing, 1-23.

Lepola, J, Lynch, J., Laakkonen, E., Silvén, M., \& Niemi, P. (2012). The Role of Inference Making and Other Language Skills in the Development of Narrative Listening Comprehension in 4-to 6-year-old Children. Reading Research Quarterly, 47(3), 259-282. doi: $10.1002 /$ rrq.020

Lever, R., \& Sénéchal, M. (2011). Discussing stories: On how a dialogic reading intervention improves kindergartners' oral narrative construction. Journal of Experimental Child Psychology, 108(1), 1-24. doi: 10.1016/j.jecp.2010.07.002

Losh, M., \& Capps, L. (2003). Narrative ability in high-functioning children with autism or Asperger's syndrome. Journal of Autism and Developmental Disorders, 33, 239-251.

Mäkinen, L., Loukusa, S., Laukkanen, P., Leinonen, E., \& Kunnari, S. (2014). Linguistic and pragmatic aspects of narration in Finnish typically developing children and children with specific language impairment. Clinical linguistics \& phonetics, 28(6), 413-427.

Mandler, J. M., \& Johnson, N. S. (1977). Remembrance of things parsed: Story structure and recall. Cognitive psychology, 9(1), 111-151.

Manolitsi, M., \& Botting, N. (2011). Language abilities in children with autism and language impairment: using narrative as an additional source of clinical information. Child Language Teaching and Therapy, 27, 39-55. 
Martin, I., \& McDonald, S. (2003). Weak coherence, no theory of mind, or executive dysfunction? Solving the puzzle of pragmatic language disorders. Brain and Language, 85, 451-466. doi: 10.1016/S0093-934X(03)00070-1.

McCabe, P. C., \& Marshall, D. J. (2006). Measuring the social competence of preschool children with specific language impairment: Correspondence among informant ratings and behavioral observations. Topics in Early Childhood Special Education, 26, 234-246.

McCabe, A., \& Rollins, R. P. (1994). Assessment of Preschool Narrative Skills. Clinical Focus. American Journal of Speech - Language Pathology, 3, 45-56. doi: 10.1044/10580360.0301.45 https://doi.org/10.1177/02711214060260040401.

McKeough, A., Bird, S., Tourigny, E., Romaine, A., Graham, S., Ottmann, J., \& Jeary, J. (2008). Storytelling as a foundation to literacy development for Aboriginal children: Culturally and developmentally appropriate practices. Canadian Psychology/Psychologie Canadienne, 49(2), 148.

Muñoz, M. L., Gillam, R. B., Peña, E. D., \& Gulley-Faehnle, A. (2003). Measures of language development in fictional narratives of Latino children. Language, Speech, and Hearing Services in Schools.

Mouzaki, A., Ralli, A. M., Antoniou, F., Diamanti, V., Papaioannou, S. (2016). Logometro: A tool for language assessment for preschool and primary school children, INTERLEARN.

Norbury, C. F., \& Bishop D. V. M. (2002). Inferential processing and story recall in children with communication problems: a comparison of specific language impairment, pragmatic language impairment and high-functioning autism. International Journal of Language \& Communication Disorders, 37(3), 227-251. doi: 10.1080/13682820210136269 
Peterson, C. (1990). The who, when, and where of early narratives. Journal of Child Language, 17, 433-455.

Peterson, C., \& McCabe, A. (1991). Linking children's connective use and narrative macrostructure. In McCabe, A. \& Peterson, C. (1991). Developing narrative structure. Hillsdale, NJ: Lawrence Erlbaum Associates.

Ralli, A. M. (2019). Language Development. Preschool, school age \& adolescence. Athens: Gutenberg.

Roch, M., Florit, E., \& Levorato, C. (2016). Narrative competence of Italian-English bilingual children between 5 and 7 years. Applied Psycholinguistics, 37(1), 49.

Saygin, Z. M., Norton, E. S., Osher, D. E., Beach, S. D., Cyr, A. B., Ozernov-Palchik, O., \& Gabrieli, J. D. (2013). Tracking the roots of reading ability: white matter volume and integrity correlate with phonological awareness in prereading and early-reading kindergarten children. Journal of Neuroscience, 33(33), 13251-13258.doi: https://doi.org/10.1523/JNEUROSCI.4383-12.2013

Schneider, P., Dubé, R. V., \& Hayward, D. (2005). The Edmonton narrative norms instrument. Retrieved from University of Alberta Faculty of Rehabilitation Medicine website: http://www. rehabresearch. ualberta. ca/enni.

Sénéchal, M., Ouellette, G., \& Rodney, D. (2006). The misunder- stood giant: On the predictive role of early vocabulary to future reading. In D.K. Dickinson \& S.B. Neuman (Eds.), Handbook of early literacy research (Vol. 2, pp. 173-182). New York: Guilford.

Skarakis-Doyle, E., Dempsey, L., \& Lee, C. (2008). Identifying Language Comprehension Impairment in Preschool Children. Language, speech and hearing services in schools, 39, 54-65. doi: 10.1044/0161-1461(2008/006).

Spencer, T. D., \& Slocum, T. A. (2010). The effect of a narrative intervention on story retelling and personal story generation skills of preschoolers with risk factors and narrative 
language delays. Journal of Early Intervention, 32(3), 178-199. doi:/10.1177/1053815110379124, 73-80

Stadler M. A., and Ward, G. C. (2005). Supporting the narrative development of young children. Early Childhood Education Journal, 33 (2), doi: 10.1007/s10643-005-0024-4

Stein, N. L., \& Glenn, C. (1979) An analysis of story comprehension in elementary schoolchildren. In R. O. Freedle (Eds.), New directions in discourse processing (pp. 53-120). Norwood, NJ: Ablex.

Vandergrift, L. (2004). Listening to learn or learning to listen? Annual Review of Applied Linguistics, 24, 3-25. doi: 10.1017/S0267190504000017

Vandewalle, E., Boets, B., Boons, T., Ghesquière, P., \& Zink, I. (2012). Oral language and narrative skills in children with specific language impairment with and without literacy delay: A three-year longitudinal study. Research in developmental disabilities, 33(6), 1857-1870. Yule, G. (2006). The study of language. (4th Eds). New York: Cambridge University Press. Wagner, R. K., Muse, A. E., \& Tannenbaum, K. R. (2007). Vocabulary acquisition: Implications for reading comprehension. Guilford Press.

Westerveld F. M., \& Gillon, T. G. (2010). Profiling oral narrative ability in young schoolaged children. International Journal of Speech-Language Pathology, 12(3), 178-189. doi: $10.3109 / 17549500903194125$ 


\section{Table 1}

Descriptive statistics on language skills by age group

\begin{tabular}{|c|c|c|c|}
\hline Age group & $4-5$ & $5-6$ & $6-7$ \\
\hline Oral language skills & $\overline{M(S D)}$ & $M(S D)$ & $M(S D)$ \\
\hline \multicolumn{4}{|l|}{ Vocabulary skills } \\
\hline Listening comprehension & $20.97(4.01)$ & $24.25(3.52)$ & $25.84(2.26)$ \\
\hline Receptive vocabulary & $47.88(8.77)$ & $55.77(6.44)$ & $59.08(3.99)$ \\
\hline Word definition & $31.22(14.78)$ & $42.70(14.83)$ & $50.21(13.70)$ \\
\hline Naming & $24.20(8.49)$ & $28.45(4.25)$ & $30.42(4.82)$ \\
\hline Phonological skills & $27.21(11.44)$ & $39.85(18.13)$ & $63(13.34)$ \\
\hline Identification of similarities task (syllable level) & $5.20(3.20)$ & $7.55(2.58)$ & $9.34(1.81)$ \\
\hline Identification of similarities task (phoneme level) & $4.48(2.39)$ & $6.37(2.82)$ & $8.72(1.57)$ \\
\hline Synthesis task (syllable level) & $7.78(2.91)$ & $8.29(2.52)$ & $9.49(1.48)$ \\
\hline Synthesis task (phoneme level) & $1.31(2.09)$ & $2.78(3.35)$ & $7.69(2.20)$ \\
\hline Syllabic segmentation & $6.59(4.26)$ & $8.18(3.10)$ & $9.14(2.16)$ \\
\hline
\end{tabular}


Phonemic segmentation

Syllabic elimination

Phonemic elimination

\section{Morphological skills}

Pragmatic skills

\section{Retelling skills (total)}

Conjunction

Lexical cohesion

Story Grammar elements

Temporal sequencing of actions \& events

$0.31(1.40)$

$1.32(2.10)$

$0.53(1.57)$

$53.34(15.87)$

65.35 (15.54)

$75.89(11.58)$

$19.36(4.46)$

$21.54(3.33)$

$23.90(4.98)$

$5.52(2.63)$

$6.52(2.64)$

$1.30(.53)$

$1.05(.44)$

$3.09(1.68)$

$1.07(.53)$

$6.12(3.15)$

$7.12(3.24)$

$5.31(3.17)$

$1.11(.63)$

$.94(.45)$

$2.47(1.54)$

$.98(.52)$
$1.51(.58)$

$1.16(.45)$

$3.47(1.58)$

$1.18(.49)$ 


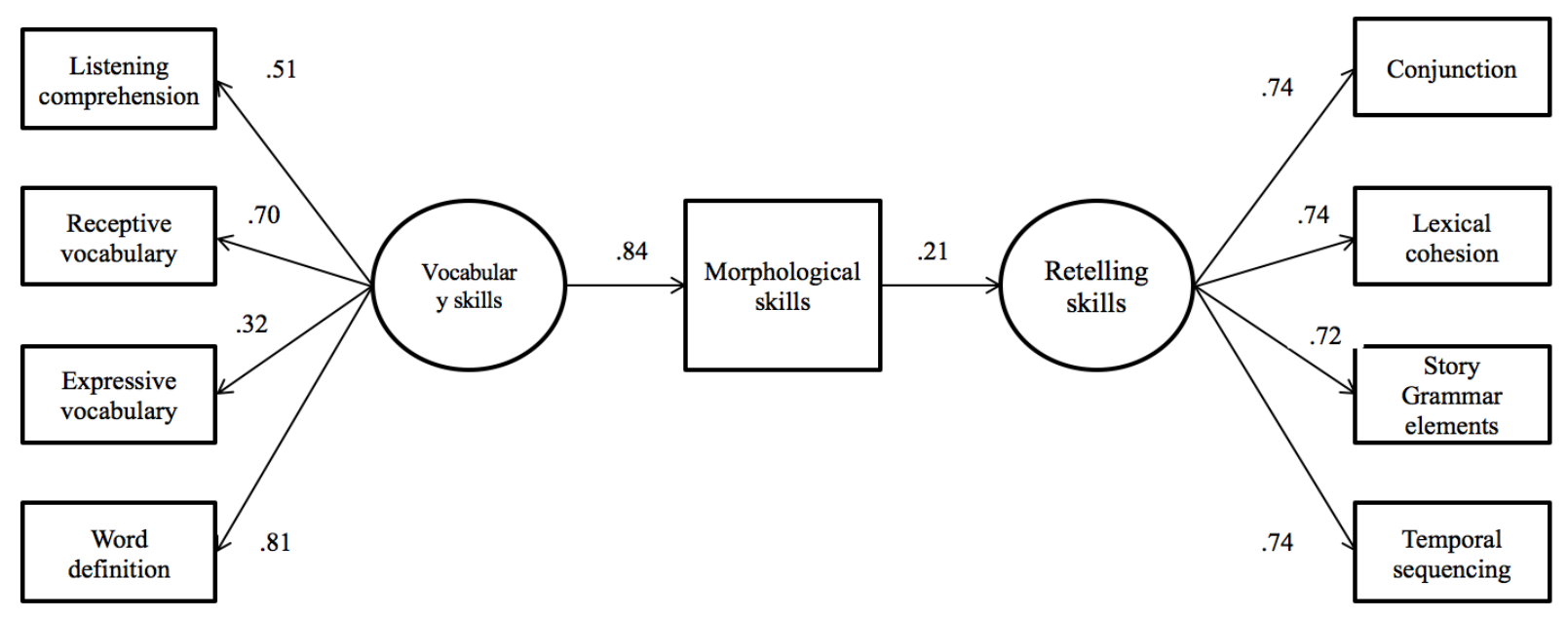

Figure 1. Model for Cohort 1 (ages 4-5) depicting relations between vocabulary skills, morphological skills, pragmatic skills, phonological skills and retelling skills. $\chi^{2}(25, N=79)$ $=35.95, p=.72\left(\chi^{2} / d f=1.44\right) ; \mathrm{CFI}=.92 ; \mathrm{NFI}=.89 ; \mathrm{GFI}=.96 ; \mathrm{RMSEA}=.08 \& \mathrm{RMR}=.08$. 


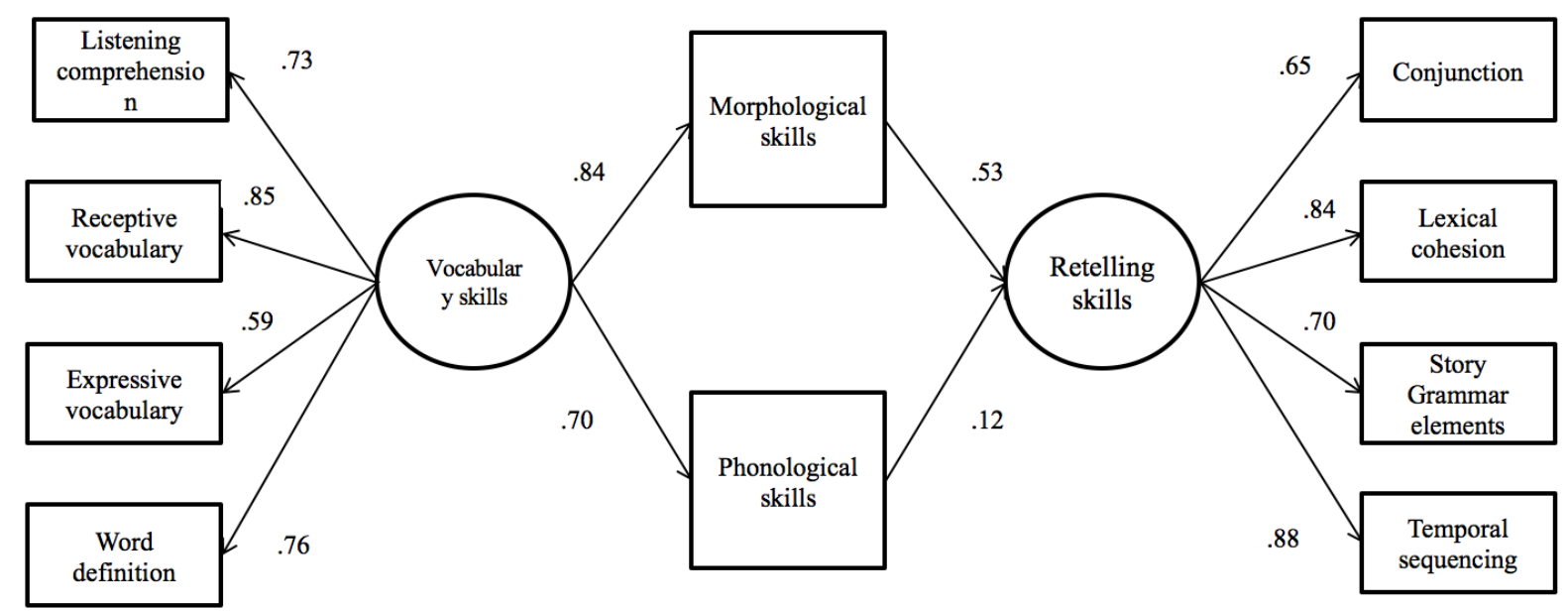

Figure 2. Model for Cohort 2 (ages 5-6) depicting relations between vocabulary skills, morphological skills, pragmatic skills, phonological skills and retelling skills. $\chi^{2}(32, N=58)$ $=31.17, p=.51\left(\chi^{2} / d f=.97\right) ; \mathrm{CFI}=1.0 ; \mathrm{NFI}=.90 ; \mathrm{GFI}=.91 ; \mathrm{RMSEA}=.00 \& \mathrm{RMR}=.07$. 


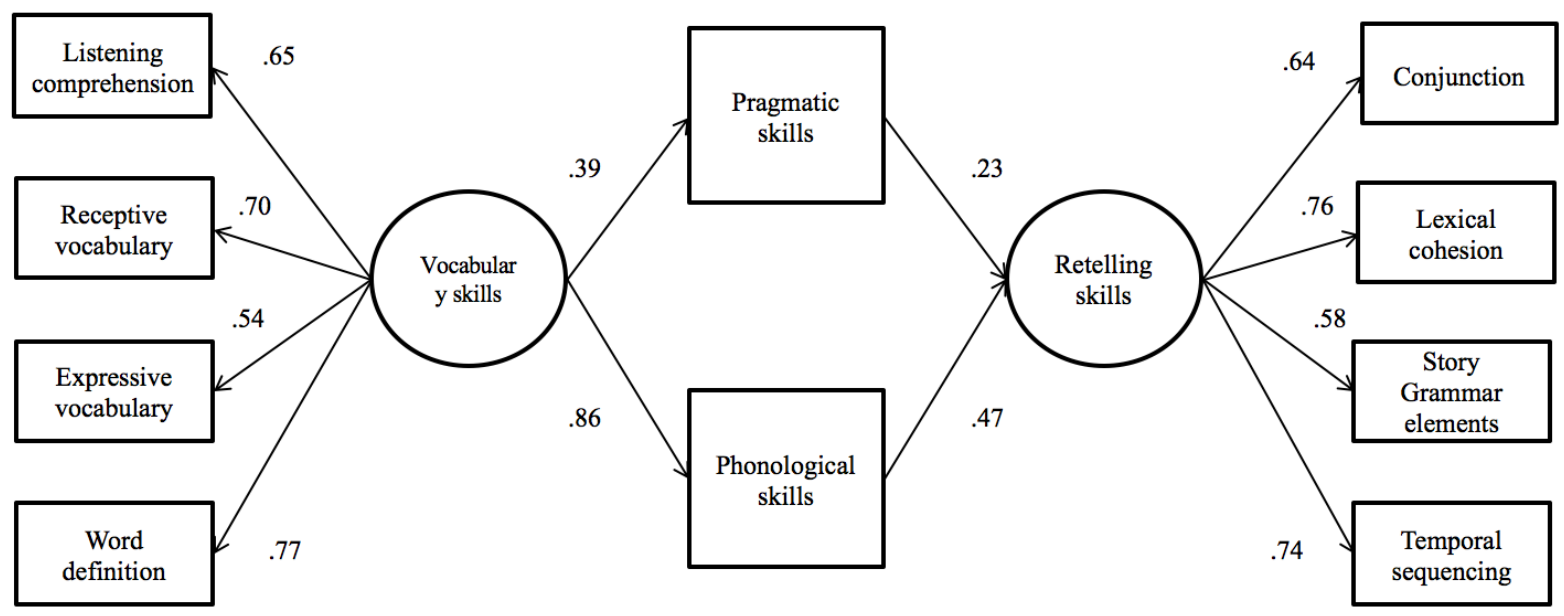

Figure 3. Model for Cohort 3 (ages 6-7) depicting relations between vocabulary skills, morphological skills, pragmatic skills, phonological skills and retelling skills. $\chi^{2}(33, \mathrm{~N}=100)$ $=29.29, \mathrm{p}=.65\left(\chi^{2} / \mathrm{df}=.89\right) ; \mathrm{CFI}=1.0 ; \mathrm{NFI}=.90 ; \mathrm{GFI}=.94 ; \mathrm{RMSEA}=.00 \& \mathrm{RMR}=.05$. 